\title{
Self-Compassion and Empathy: Impact on Burnout and Secondary Traumatic Stress in Medical Training
}

\author{
David A. Richardson1, Sara Jaber ${ }^{1}$, Sarah Chan1, Michelle T. Jesse ${ }^{2}$, Hareena Kaur ${ }^{1}$, \\ Roopina Sangha 1 \\ ${ }^{1}$ Department of Obstetrics and Gynecology, Henry Ford Hospital/Wayne State University, Detroit, USA \\ ${ }^{2}$ Transplant Institute and Behavioral Health Services (dual appointments), Henry Ford Health System, Detroit, USA

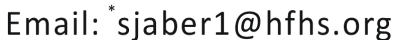

Received 20 June 2016; accepted 7 August 2016; published 10 August 2016

Copyright (C) 2016 by authors and Scientific Research Publishing Inc.

This work is licensed under the Creative Commons Attribution International License (CC BY).

http://creativecommons.org/licenses/by/4.0/

c) (i) Open Access

\begin{abstract}
Objective: To determine how self-compassion and empathy might influence the degree of burnout, secondary traumatic stress and compassion satisfaction among medical students and residents. Methods: Cross-sectional survey of medical students and select residency programs at Henry Ford Hospital in Detroit, Michigan. Respondents completed the Professional Quality of Life Scale (burnout, secondary traumatic stress and compassion satisfaction), Neff's Self-Compassion Scale, and the empathic concern and personal distress subscales of the Interpersonal Reactivity Index. Results: The response rate was $28.6 \% .23 .9 \%$ and $27.3 \%$ of medical trainees reported high levels of burnout and secondary traumatic stress, respectively. Females reported greater empathy but lower self-compassion than males. Greater concern for others and oneself and lower personal distress predicted greater pleasure derived from professional work. Less concern for others and lower concern for oneself predicted greater burnout. Conclusions: Compassion for oneself and for others within their care appears to ameliorate burnout and can increase professional satisfaction. Initiatives to foster empathy and self-compassion may enhance individual well-being.
\end{abstract}

\section{Keywords}

Burnout, Secondary Traumatic Stress, Empathy, Self-Compassion, Well-Being

\section{Introduction}

Estimates of burnout in medical education have ranged from $28 \%-45 \%$ in medical students and $27 \%-75 \%$ in ${ }^{*}$ Corresponding author.

How to cite this paper: Richardson, D.A., Jaber, S., Chan, S., Jesse, M.T., Kaur, H. and Sangha, R. (2016) Self-Compassion and Empathy: Impact on Burnout and Secondary Traumatic Stress in Medical Training. Open Journal of Epidemiology, 6, 161-166. http://dx.doi.org/10.4236/ojepi.2016.63017 
residents [1]. Secondary traumatic stress, less frequently studied, is defined as the emotional and physical consequence of direct or indirect exposure to significant events that often occur in medical settings including acute medical traumas, victims of abuse, patient/fetal deaths, angry patients and medical errors [2]. Estimates of secondary traumatic stress approach $30 \%$ in physicians [3]. In some cases, exposure to these events can produce symptomatology such as fear, loss of confidence, irritability/anger, depression, anxiety, and sleep difficulties [4].

Empathy, or concern for others, is an indispensable competency for individuals engaged in a healing profession. Historically, there was a belief that empathy might lead to provider burnout. This was used as a justification to encourage physicians to develop an emotional detachment from patients. However, recent studies suggest that empathy may be protective against burnout and secondary traumatic stress.

Alternatively, concern for oneself or self-compassion has recently been conceptualized as having three components: 1) treating ourselves with kindness and understanding when we have failed or made mistakes, 2) seeing our own pain and suffering as part of a larger human experience-recognizing that life is not perfect and 3) allowing ourselves to experience feelings as they are without suppressing or avoiding them [5]. Recent literature demonstrates a strong relationship between self-compassion and decreased stress, anxiety, and depression [6]. Self-compassion is associated with greater emotional resilience and the ability of individuals to cope with difficult and stressful emotional experiences such as post-traumatic stress disorder [7]. Little is known about the influence of self-compassion on medical trainees.

The objective of this study was to determine how empathy and self-compassion might influence the degree of burnout, secondary traumatic stress and compassion satisfaction among medical students and residents (combined).

\section{Methods}

All residents in the Departments of Obstetrics and Gynecology, General Surgery, Emergency Medicine and Internal Medicine at the Henry Ford Health System enrolled in the academic year 2013-2014 were eligible to participate in the study. All third year Wayne State University medical students participating in their clinical rotations at Henry Ford Hospital were eligible to participate at the conclusion of the academic year.

All data was collected with full Henry Ford Health System Institutional Review Board approval. Residents and medical students were recruited via an email explaining the purpose of the study and a link to a secured external website with the survey (www.surveymonkey.com). Both the recruitment email and the first page of the electronic link explained that the study was voluntary and participation indicated consent. Two waves of recruitment emails were sent, approximately 2 weeks apart, to maximize recruitment. The survey included questions about age, specialty, level of training, hours spent at home on work related activities, relationship status, children, and exercise. Validated survey tools, described below, were used to evaluate compassion satisfaction, burnout, secondary traumatic stress, empathic concern, personal distress and self-compassion.

The Professional Quality of Life Scale Version 5 (PROQOL; Version 5) is a validated, psychometrically sound 30-item instrument that assesses for compassion satisfaction (pleasure or satisfaction derived from work), burnout (exhaustion and frustration), and secondary traumatic stress (work related secondary exposure to trauma) [8]. Questions assess for positive and negative emotions related to work experiences within the past 30 days. Responses are based on a 5-point Likert scale from 1 ("never") to 5 ("very often”). Scores were calculated for each of the 3 subscales in accordance with the PROQOL manual, which includes established cut-offs for categorization into top quartile (or high), mean (or moderate), and bottom quartile (low) scores. Higher scores indicate greater compassion satisfaction, burnout, or secondary traumatic stress.

The Interpersonal Reactivity Index (IRI) is a validated 28-item instrument consisting of 4 subscales that are used to measure the emotional and cognitive components of a person's general capacity for empathy [9]. For the purposes of our study, we focused on 2 of the Interpersonal Reactivity Index scales (14 questions total): empathic concern and personal distress. Respondents are given the response options of alphabetical letters from A (“does not describe me well”) to E (“describes me very well”). Responses were then appropriately recoded and the subscales were summed for a total empathic concern or personal distress score. Higher scores indicate greater empathic concern or greater personal distress.

The Self-Compassion Scale-Short Form (SCS) is a 12-item validated instrument used to measure the degree of compassion an individual exhibits toward themselves in instances of failure or emotional distress [10]. Res- 
ponses are based on a 5-point Likert scale from 1 (“almost never”) to 5 (“almost always”). Scores are summed and divided into 6 subscales: self-kindness, self-judgment, common humanity, mindfulness, over-identification, and isolation. Higher scores on each subscale indicate greater levels of self-kindness, self-judgment, common humanity, mindfulness, over-identification, and isolation. Recoding the negatively themed subscale items (selfjudgment, isolation, and over-identification) and summing all items provides an overall self-compassion score.

Analyses were conducted using SPSS Version 22 (IBM Corporation, New York, NY). Descriptive statistics were run for all variables. Bivariate analyses were conducted to examine whether there were significant relationships between individual variables, to check for redundancy, and to test for outcomes that have significance. Lastly, we performed 3 multiple linear regressions with the 3 subscales of the PROQOL (burnout, secondary traumatic stress, and compassion satisfaction) as outcomes and predictor variables were selected based upon significant $(P<0.05)$ or approaching significant $(P<0.1)$ bivariate relationship with the outcome of interest.

\section{Results}

Of the 307 medical students and residents recruited, 88 provided adequate data to be included in the analyses (28.6\% response rate). Across all trainees, 23.9\% reported high burnout and 27.3\% reported high secondary traumatic stress. However, of the total sample, $11.4 \%$ were categorized as both high burnout and high secondary traumatic stress. Low self-compassion was noted in $30 \%$ and decreased compassion satisfaction in $30.7 \%$ of the respondents.

The mean age of the respondents was $28.48 \pm 3.08$ years. $48.9 \%$ were female responders. Among the specialties that replied, $27.3 \%$ were third year medical students, $10.2 \%$ Obstetrics and Gynecology residents, 30.7\% Internal Medicine residents, 22.7\% Emergency Medicine residents, and 9.1\% General Surgery residents. 47.7\% of the respondents were married or cohabitating while $52.3 \%$ were single or unmarried. $17 \%$ of the interviewees had children. $54.5 \%$ of the respondents reported that they exercised regularly.

Correlations between continuous variables are presented in Table 1. Correlations between the subscales of the Self-Compassion Scale and outcomes of interest (compassion satisfaction, burnout, and secondary traumatic stress) are presented in Table 2.

Table 1. Correlations between continuous variables.

\begin{tabular}{ccccccc}
\hline & 2. & 3. & 4. & 5. & 6. & 7. \\
\hline 1. Age & -0.005 & 0.076 & -0.105 & -0.076 & $-0.213^{\ddagger}$ & -0.060 \\
2. Compassion satisfaction & & $-0.758^{* *}$ & $-0.196^{\ddagger}$ & $0.354^{* *}$ & $-0.215^{*}$ & $0.286^{*}$ \\
3. Burnout & & & $0.438^{* *}$ & $-0.249^{*}$ & $0.208^{\ddagger}$ & $-0.405^{* *}$ \\
4. Secondary traumatic stress & & & & 0.126 & $0.443^{* *}$ & $-0.284^{*}$ \\
5. IRI: empathic concern & & & & & 0.144 & -0.032 \\
6. IRI: personal distress & & & & & $-0.255^{*}$ \\
7. Self-compassion & & & & & \\
\hline
\end{tabular}

IRI = Interpersonal Reactivity Index. Note. ${ }^{*} P \leq 0.05,{ }^{* *} P \leq 0.001,{ }^{\ddagger} P>0.05$ but $<0.10$; scores for compassion satisfaction, burnout, and secondary traumatic stress are converted to t-scores; self-compassion score is for the total score.

Table 2. Correlations between self-compassion subscales and outcomes.

\begin{tabular}{cccc}
\hline Self-Compassion Subscale & Compassion Satisfaction & Burnout & Secondary Traumatic Stress \\
\hline Self-kindness & $0.222^{*}$ & $-0.335^{* *}$ & $-0.203^{\ddagger}$ \\
Self-judgment & $-0.237^{*}$ & $0.371^{* *}$ & $0.243^{*}$ \\
Common humanity & 0.094 & -0.034 & 0.009 \\
Isolation & $-0.314^{*}$ & $0.414^{* *}$ & $0.222^{*}$ \\
Mindfulness & $0.189^{\ddagger}$ & $-0.267^{*}$ & $-0.237^{*}$ \\
Over-identification & -0.191 & $0.332^{*}$ & $0.237^{*}$ \\
\hline
\end{tabular}

Note. ${ }^{*} P \leq 0.05,{ }^{* *} P \leq 0.001,{ }^{\ddagger} P>0.05$ but $<0.10$; scores for compassion satisfaction, burnout, and secondary traumatic stress are converted to t-scores. 
Next, we ran a series of student t-tests or analyses of variance (ANOVA) to examine for significant differences based upon gender, level of training, training program, relationship status, and presence of children in the home on burnout, secondary traumatic stress, or compassion satisfaction. There were several significant differences for gender. Females reported significantly higher secondary traumatic stress $(52.32 \pm 10.58)$ than males (47.51 \pm 8.89) with a $P=0.02$ [95\% CI 0.64, 8.97] and significantly higher empathic concern (20.70 \pm 4.55$)$ than males (18.63 \pm 4.17$), P=0.03$. There appeared to be a significant difference on self-compassion between females (34.17 \pm 8.08$)$ and males (37.57 \pm 7.53$), P=0.05$, but the confidence intervals suggested this was an erroneous finding [95\% CI $-0.01,6.8]$. There was no significant difference on personal distress based upon gender. Medical students reported significantly greater personal distress $(9.00 \pm 4.05)$ than residents $(6.43 \pm 4.98)$ with $P=0.03$ [95\% CI 0.22, 4.92]. There were no significant differences between medical students and residents with regards to empathic concern or self-compassion. Among the residents, there were no significant differences between training programs. There were no significant differences on any of the variables based upon relationship status or presence of children in the home.

Lastly, we performed three multiple linear regressions on the outcomes of interest: compassion satisfaction, burnout, and secondary traumatic stress (Table 3). No statistical assumptions were violated for any of the models. For compassion satisfaction, the final model included empathic concern, personal distress and self-compassion, all of which were statistically significant. Greater empathic concern, reduced personal distress, and greater self-compassion all significantly predicted compassion satisfaction $(P \leq 0.05)$. For burnout, the model included empathic concern, personal distress, and self-compassion, of which only empathic concern and self-compassion were significant. Lower levels of empathic concern and self-compassion significantly predicted burnout ( $P \leq$ 0.05). For secondary traumatic stress, the model included gender, personal distress and self-compassion; personal distress was significant $(P \leq 0.01)$ while gender and self-compassion were approaching significance $(P=0.08$ and $P=0.07$, respectively).

\section{Discussion}

The levels of resident and student burnout are consistent with previously reported data in the literature. Age, gender, relationship status, children and training level were not significantly related to burnout; this is consistent with previously published literature [11]. The lack of relationship between gender and burnout is a particularly interesting one given prior literature suggesting female physicians report higher levels of burnout than male physicians [12]. This study goes beyond previously reported research on trainees by looking at the degree of secondary traumatic stress and its relationship to burnout. The relationship between secondary traumatic stress and increased burnout with decreased compassion satisfaction is consistent with findings reported in other health care workers [13] [14]. Although we did not find significant differences between third year medical students and residents on secondary traumatic stress, burnout, and compassion satisfaction, given the design of our study and limited sample size, we cannot conclude whether these change over the course of training. However, further longitudinal research is warranted exploring whether and how these change over time.

Table 3. Multiple linear regressions with the 3 subscales of the professional quality of life scale.

\begin{tabular}{|c|c|c|c|c|c|c|c|c|c|c|c|c|}
\hline & \multicolumn{4}{|c|}{$\begin{array}{l}\text { Compassion Satisfaction } \\
F(3,80), R^{2} a d j=0.210, P<0.001\end{array}$} & \multicolumn{4}{|c|}{$\begin{array}{c}\text { Burnout } \\
F(3,80), R^{2} a d j=0.197, P<0.001\end{array}$} & \multicolumn{4}{|c|}{$\begin{array}{c}\text { Secondary Traumatic Stress } \\
F(3,79), R^{2} \text { adj }=0.250, P<0.001\end{array}$} \\
\hline & B & SE(B) & $\beta$ & B 95\% CI & B & $\mathrm{SE}(\mathrm{B})$ & $\beta$ & B 95\% CI & B & SE(B) & $\beta$ & B CI \\
\hline Gender & - & - & - & - & - & - & - & - & 3.394 & 1.953 & $0.171^{\ddagger}$ & $\begin{array}{c}{[-0.493} \\
7.282]\end{array}$ \\
\hline $\begin{array}{l}\text { IRI: empathic } \\
\text { concern }\end{array}$ & 0.836 & 0.222 & $0.372^{* *}$ & {$[0.395,1.277]$} & -0.492 & 0.216 & $-0.227^{*}$ & $\begin{array}{l}{[-0.992} \\
-0.062]\end{array}$ & - & - & - & - \\
\hline $\begin{array}{l}\text { IRI: personal } \\
\text { distress }\end{array}$ & -0.425 & 0.210 & $-0.207^{*}$ & $\begin{array}{l}{[-0.842} \\
-0.008]\end{array}$ & 0.289 & 0.204 & 0.145 & $\begin{array}{c}{[-0.117,} \\
0.696]\end{array}$ & 0.792 & 0.204 & $0.386^{* * *}$ & {$[0.387,1.198]$} \\
\hline $\begin{array}{l}\text { Self-compassion } \\
\text { total }\end{array}$ & 0.303 & 0.125 & $0.245^{*}$ & {$[0.054,0.552]$} & -0.449 & 0.122 & $-0.375^{* *}$ & $\begin{array}{l}{[-0.691} \\
-0.207]\end{array}$ & -0.227 & 0.126 & $-0.181^{\ddagger}$ & $\begin{array}{c}{[-0.478,} \\
0.024]\end{array}$ \\
\hline
\end{tabular}

IRI = Interpersonal Reactivity Index. Note. ${ }^{*} P \leq 0.05,{ }^{* *} P \leq 0.01,{ }^{\ddagger} P>0.05$ but $<0.10$; scores for compassion satisfaction, burnout, and secondary traumatic stress are converted to t-scores; “—“ “ indicates not included in the model for that outcome based upon non-significant bivariate findings. 
The relationships between self-compassion and secondary traumatic stress, burnout, and compassion satisfaction have not been previously documented in medical students and residents. Prior research in other populations has indicated less stress, depression, and anxiety and greater emotional resilience are associated with greater self-compassion [7]. The positive relationship between both self-compassion and empathy with compassion satisfaction supports observations in the literature that taking a mindful, kind and nonjudgmental stance toward ourselves and others could enable us to derive more enjoyment in our work as healers [15].

The results support the literature suggesting that empathy is protective against burnout and fosters compassion satisfaction. One might have expected that individuals with higher empathic concern would be more susceptible to secondary traumatic stress. Our data demonstrate a non-significant relationship between empathic concern and secondary traumatic stress suggesting that when individuals witness traumatic occurrences that their responses are independent of their degree of empathy.

This relationship between the subscales of self-compassion and our primary outcome measures supports the proposition that the culture of shame and blame increases an individual's propensity for burnout. Experiential avoidance, self-judgment, isolation, and over identification are related to burnout and have a negative impact on emotional well-being [7]. For physicians in training, mistakes happen and situations will occur beyond their control. In these circumstances, self-compassion teaches individuals to acknowledge the situation with mindful awareness and accept their emotional response with kindness and without judgment as part of our common humanity [16].

There are two main limitations to this study; the greatest limitation is the relatively small sample size, which limits generalizability. Secondly and related, the overall models accounted for a relatively small proportion of the variance. Within the social sciences this is a common enough occurrence, but clearly further research with larger sample sizes examining these variables over time is warranted. There are likely other variables which contribute to the development of the outcomes of interest. Also, the constructs of burnout, secondary traumatic stress and compassion satisfaction are most likely fluid within any individual over time and as such longitudinal style data would be useful in determining how these develop.

Medical curricula commonly provide communication courses to aid in dealing with difficult, angry or grieving patients. Rarely are trainees taught how to deal with their own feelings of fear, anger, shame, inadequacy, or failure. Mindful based stress reduction, mindful self-compassion, compassion focused therapy, acceptance commitment therapy, and other programs that foster emotional resilience have demonstrated a decrease in burnout and increase in self-compassion [17]-[19]. Interventions to foster self-compassion have demonstrated significant improvement in happiness, life satisfaction, and compassion for others [16]. Preemptively teaching trainees how to effectively deal with their emotions may be necessary to decrease burnout and secondary traumatic stress.

\section{Conclusion}

This study supports emerging data that teaching self-compassion and empathy may increase physician well-being by decreasing burnout and secondary traumatic stress. The importance of this work is the recognition that measures exist to prevent burnout by coaching empathy and self-compassion to our trainees.

\section{Declaration of Interest}

The authors report no declarations of interest.

\section{References}

[1] Ishak, W.W., Lederer, S., Mandili, C., et al. (2009) Burnout during Residency Training: A Literature Review. The Journal of Graduate Medical Education, 1, 236-242. http://dx.doi.org/10.4300/JGME-D-09-00054.1

[2] Gazoni, F.M., Amato, P.E., Malik, Z.M. and Durieux, M.E. (2012) The Impact of Perioperative Catastrophes on Anesthesiologists: Results of a National Survey. Anesthesia \& Analgesia, 114, 596-603. http://dx.doi.org/10.1213/ANE.0b013e318227524e

[3] Scott, S.D., Hirschinger, L.E., Cox, K.R., et al. (2010) Caring for Our Own: Deploying a Systemwide Second Victim Rapid Response Team. The Joint Commission Journal on Quality and Patient Safety, 36, 233-240.

[4] Waterman, A.D., Garbutt, J., Hazel, E., et al. (2007) The Emotional Impact of Medical Errors on Practicing Physicians in the United States and Canada. The Joint Commission Journal on Quality and Patient Safety, 33, 467-476. 
[5] Neff, K.D. (2003) Self-Compassion: An Alternative Conceptualization of a Healthy Attitude toward Oneself. Self and Identity, 2, 85-101. http://dx.doi.org/10.1080/15298860309032

[6] MacBeth, A. and Gumley, A. (2012) Exploring Compassion: A Meta-Analysis of the Association between Self-Compassion and Psychopathology. Clinical Psychology Review, 32, 545-552. http://dx.doi.org/10.1016/j.cpr.2012.06.003

[7] Barnard, L.K. and Curry, J.F. (2011) Self-Compassion: Conceptualizations, Correlates, and Interventions. Review of General Psychology, 15, 289-303. http://dx.doi.org/10.1037/a0025754

[8] Stamm, B.H. (2009-2012) Professional Quality of Life: Compassion Satisfaction and Fatigue Version 5 (ProQOL). www.proqol.org

[9] Davis, M. (1983) Measuring Individual Differences in Empathy: Evidence for a Multidimensional Approach. Journal of Personality and Social Psychology, 44, 113-126. http://dx.doi.org/10.1037/0022-3514.44.1.113

[10] Raes, F., Pommier, E., Neff, K.D. and Van Gucht, D. (2011) Construction and Factorial Validation of a Short Form of the Self-Compassion Scale. Clinical Psychology and Psychotherapy, 18, 250-255. http://dx.doi.org/10.1002/cpp.702

[11] West, C.P., Shanafelt, T.D. and Kolars, J.C. (2011) Quality of Life, Burnout, Educational Debt, and Medical Knowledge among Internal Medicine Residents. JAMA, 306, 952-960. http://dx.doi.org/10.1001/jama.2011.1247

[12] Kuerer, H.M., Eberlein, T.J., Pollock, R.E., et al. (2011) Burnout among Surgical Oncologists: Report on the Quality of Life of Members of the Society of Surgical Oncology. Annals of Surgical Oncology, 14, 3043-3053. http://dx.doi.org/10.1245/s10434-007-9579-1

[13] Sheen, K., Slade, P. and Spiby, H. (2014) An Integrative Review of the Impact of Indirect Trauma Exposure in Health Professionals and Potential Issues of Salience for Midwives. Journal of Advanced Nursing, 70, 729-743. http://dx.doi.org/10.1111/jan.12274

[14] Robins, P.M., Meltzer, L. and Zelikovsky, N. (2009) The Experience of Secondary Traumatic Stress upon Care Providers Working within a Children’s Hospital. Journal of Pediatric Nursing, 24, 270-279. http://dx.doi.org/10.1016/j.pedn.2008.03.007

[15] Barnard, L.K. and Curry, J.F. (2011) The Relationship of Clergy Burnout to Self-Compassion and Other Personality Dimensions. Pastoral Psychology, 61, 149-163. http://dx.doi.org/10.1007/s11089-011-0377-0

[16] Raab, K. (2014) Mindfulness, Self-Compassion, and Empathy among Health Care Professionals: A Review of the Literature. Journal of Health Care Chaplaincy, 20, 95-108. http://dx.doi.org/10.1080/08854726.2014.913876

[17] Krasner, M.S., Epstein, R.M., Beckman, H., et al. (2009) Association of an Educational Program in Mindful Communication with Burnout, Empathy, and Attitudes among Primary Care Physicians. JAMA, 302, 1284-1293. http://dx.doi.org/10.1001/jama.2009.1384

[18] Shapiro, S.L., Astin, J.A., Bishop, S.R. and Cordova, M. (2005) Mindfulness-Based Stress Reduction for Health Care Professionals: Results from a Randomized Trial. International Journal of Stress Management, 12, 164-176. http://dx.doi.org/10.1037/1072-5245.12.2.164

[19] Kearney, D.J., Malte, C.A., McManus, C., Martinez, M.E., Felleman, B. and Simpson, T.L. (2013) Loving-Kindness Meditation for Posttraumatic Stress Disorder: A Pilot Study. Journal of Traumatic Stress, 26, 426-434. http://dx.doi.org/10.1002/jts.21832

\section{Submit or recommend next manuscript to SCIRP and we will provide best service for you:}

Accepting pre-submission inquiries through Email, Facebook, LinkedIn, Twitter, etc.

A wide selection of journals (inclusive of 9 subjects, more than 200 journals)

Providing 24-hour high-quality service

User-friendly online submission system

Fair and swift peer-review system

Efficient typesetting and proofreading procedure

Display of the result of downloads and visits, as well as the number of cited articles

Maximum dissemination of your research work

Submit your manuscript at: http://papersubmission.scirp.org/ 